\section{The squeeze test of MCP joints: a scarcity of scientific data, especially from primary care}

We thank Vega-Moralis et $a l^{1}$ for their interest in the EULAR definition of arthralgia suspicious for progression to rheumatoid arthritis (RA). ${ }^{2}$ The definition is composed of seven parameters and the authors are particularly interested in the parameter 'presence of a positive squeeze test of metacarpal joints'. They suggest that the squeeze test can be used in primary care to promote referral to secondary care, and they have developed an automated test. ${ }^{1}$

First of all, we want to underline that the EULAR definition of arthralgia suspicious for progression to RA is developed for use in secondary care. ${ }^{2}$ If the definition is also valuable for use in primary care needs to be determined. In addition, although the squeeze test is commonly used in daily practice, it is striking that there is not much scientific data on this test. A recent study performed in secondary care showed that the squeeze test of the MCP joints had a specificity $>80 \%$, but a low sensitivity. ${ }^{3}$ To our knowledge, the performance of this test has never been studied in primary care. Although intuitively the squeeze test is believed valuable in decisions on referral, presently this is not supported by scientific data. There is also no evidence than an automated squeeze test performs better than manual squeezing of MCP joints. Although clinical evaluation is the basis of medicine, from many simple tests the test characteristics are insufficiently known. The squeeze test is an example that requires further studies, especially when the test is used in primary care.

\section{A H M van der Helm-van Mil ${ }^{1,2}$}

${ }^{1}$ Department of Rheumatology, Leiden University Medical Center, Leiden, The Netherlands
2Department of Rheumatology, Erasmus Medical Center, Rotterdam, The Netherlands

Correspondence to A H M van der Helm-van Mil, Department of Rheumatology, Leiden University Medical Center, Leiden and Erasmus Medical Center, Rotterdam 2300 RC, The Netherlands; AvdHelm@lumc.nl

Competing interests None declared.

Provenance and peer review Commissioned; internally peer reviewed.

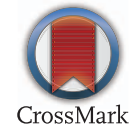

To cite van der Helm-van Mil AHM. Ann Rheum Dis 2017;76:e41.

Accepted 5 February 2017

Published Online First 27 February 2017

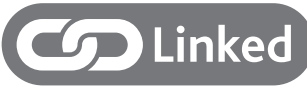

http://dx.doi.org/10.1136/annrheumdis-2017-211205

Ann Rheum Dis 2017;76:e41. doi:10.1136/annrheumdis-2016-211230

\section{REFERENCES}

1 Vega-Moralis D, Esquivel-Valerio JA, Arana-Guajardo AC. Automated Squeeze test (Gaenslens maneuver) to identify suspicious arthralgia patients: Improving Time Delay to Rheumatology Consultation. Ann Rheum Dis 2017;76:e40.

2 van Steenbergen HW, Aletaha D, Beaart-van de Voorde LJ, et al. EULAR definition of arthralgia suspicious for progression to rheumatoid arthritis. Ann Rheum Dis 2017;76:491-6.

3 Bosch WB van den, Mangnus L, et al. The diagnostic accuracy of the squeeze test to identify arthritis: a cross-sectional cohort study. Ann Rheum Dis 2015;74:1886-9. 